\title{
EFFECTIVENESS OF VAGINAL VERSUS BUCCAL MISOPROSTOL FOR FIRST TRIMESTER INDUCED ABORTIONS- A COMPARATIVE STUDY
}

\author{
Zareena Hassan Khan'1, Sameena Akhter², Shashi Gupta ${ }^{3}$ \\ ${ }^{1}$ Consultant Gynaecologist, Post-Partum Center, Department of Gynaecology \& Obstetrics, GMC, Jammu, J \& K, India. \\ ${ }^{2}$ Medical Officer (Anaesthetist), Department of Health, J \& K, India. \\ 3 Professor \& HOD, Department of Gynaecology \& Obstetrics, GMC, Jammu, J \& K, India.
}

\begin{abstract}
\section{BACKGROUND}

Abortion can be induced by medical or surgical methods, of which medical abortion is safer, including misoprostol, administered by various routes. Vaginal administration, although effective, may require repeated vaginal examinations, being inconvenient and unacceptable at times. This has paved way for other routes of misoprostol administration such as buccal and sublingual, with additional benefits including ease of administration and lesser infection rate.

Objectives- To compare the safety, effectiveness and patient satisfaction of vaginal and buccal misoprostol in first trimester induced abortion.
\end{abstract}

\section{MATERIALS AND METHODS}

A prospective randomised study in hundred women undergoing first trimester induced abortion up to 49 days were divided into two groups. Group A, with 50 patients, were given oral mifepristone (200 mg) followed by vaginal misoprostol (800 mcg). Group B, with 50 patients, were given oral mifepristone $(200 \mathrm{mg}$ ) followed by buccal misoprostol $(800 \mathrm{mcg})$. Results were compared in both the groups in term of safety, effectiveness and patient satisfaction.

\section{RESULTS}

In both the groups, first trimester induced abortions up to 49 days (7 weeks) were safe. The efficacy as judged by complete abortion was $88 \%$ in group A (vaginal) and was $94 \%$ in group B (buccal). No statistical significant difference in safety and complete abortion was observed. Statistical significant adverse effects noticed was altered taste in group B (buccal). No statistical significant difference in patient satisfaction in both groups was observed.

\section{CONCLUSION}

Vaginal and buccal misoprostol have similar efficacy and patient satisfaction. For first trimester induced abortion, buccal route can be used as an effective alternative.

\section{KEYWORDS}

Misoprostol, Buccal, Vaginal, Abortion.

HOW TO CITE THIS ARTICLE: Khan ZH, Akhter S, Gupta S. Effectiveness of vaginal versus buccal misoprostol for first trimester induced abortions: a comparative study. J. Evolution Med. Dent. Sci. 2017;6(59):4363-4366, DOI: 10.14260/Jemds/2017/943

\section{BACKGROUND}

The first recorded evidence of induced abortion was from Egyptian Eber Papyrus in 1550 BC.[1,2] Over 5000 years ago, the Chinese Emperor Shen Nung described the use of mercury for inducing abortion.[3] Most abortion-related maternal deaths are attributable to illegal abortions. According to the Consortium of National Consensus for Medical abortion in India, every year an average about 11 million abortions take place and around 20000 women die every year due to abortion related complications. [4] In order to reduce the number of unsafe abortions, the Government of India passed MTP Act in 1971 which came into force from April 2, 1972 and the rules were modified in 2003 to strengthen the MTP Act.[5] Medical abortion is a safe alternative to surgical abortion. Various regimens have been

Financial or Other, Competing Interest: None.

Submission 06-06-2017, Peer Review 12-07-2017,

Acceptance 18-07-2017, Published 24-07-2017.

Corresponding Author:

Dr. Zareena Hassan Khan,

House No 194-A, Ustad Mohalla,

Jammu-180001, Jammu \& Kashmir.

E-mail: zareenahkhan2000@gmail.com

DOI: $10.14260 /$ jemds $/ 2017 / 943$

\section{(c) $(1) \ominus$}

proposed for the administration of the mifepristone and misoprostol combination. The DCGI recently approved a combi-pack of one $200 \mathrm{mg}$ tablet of mifepristone and four $200 \mathrm{mcg}$ tablets of misoprostol for medical method of abortion up to 63 days.[6]

It was found in clinical studies that vaginal route of misoprostol administration was more effective than oral administration in medical abortion. Although effective, vaginal administration may require repeated vaginal examinations which are inconvenient and may not be acceptable for many patients. This has led to studies of other routes of misoprostol administration such as buccal and sublingual.[7] Additional benefits of the buccal route over the vaginal route include its ease of administration and lesser infection rate.[8]

This study was undertaken to determine the effectiveness, side effects and patient satisfaction of buccal route of misoprostol as an alternative to vaginal administration of misoprostol for first trimester induced abortion.

\section{MATERIALS AND METHODS}

This prospective randomised study was carried out in the Department of Obstetrics and Gynaecology of Government 
Medical College, Jammu for a three months' period from October to December 2016 after obtaining permission from the institutional ethical committee of the institution. A total of 100 pregnant women with gestational period of less than 49 days admitted for induced abortion were included in the study. Women were explained about the medical and surgical treatment and written consent was taken regarding the dose of the drug, the side effects, the number of visits required, and need for surgical intervention in case of failure. The women were further randomised into two groups of 50 each, Group A (vaginal group) and Group B (Buccal group). The allocation in the two groups was done as per the random number sequence generated in Microsoft Excel. Guidelines and indications for abortion were the same as stipulated under MTP Act 1971 and modified in 2003.

\section{Inclusion Criteria}

Confirmed pregnancy of less than 49 days of gestation in patients of 18 years of age or older who were willing to come back to the hospital for 1-3 followups and agreed to have a surgical abortion if the medical abortion fails.

\section{Exclusion Criteria}

Patients with suspected ectopic pregnancy, history of allergy to either mifepristone or misoprostol, hypertension, severe hepatic or renal disease, severe anaemia, chronic systemic use of corticosteroids, chronic adrenal failure, coagulopathy, current therapy with anticoagulant and inherited porphyrias.

\section{Procedure Followed}

A detailed history was followed by recording of vital baseline parameters like pulse, BP, temperature. Detailed per abdomen, per speculum and per vaginal examination were done. The haematological investigation included haemogram, blood grouping and typing, urine routine examination, blood sugar level (fasting and random), HBsAg, VDRL and HIV. An ultrasound was performed to confirm the period of gestation. Following medical regimen was followed.

\section{Group A (Vaginal Group)}

Day 1 - Tab. Mifepristone $200 \mathrm{mg}$ orally.

Day 3 - Tab. Misoprostol $800 \mathrm{mcg}$ (four tabs. of $200 \mathrm{mcg}$ each) placed vaginally in posterior fornix.

\section{Group B (Buccal Group)}

Day 1 - Tab. Mifepristone $200 \mathrm{mg}$ orally.

Day 3 - Tab. Misoprostol 800 mcg (four tabs each 200 $\mathrm{mcg}$ ) were placed in buccal fold i.e. between teeth and cheek (2 on each side).

Subjects were instructed to swallow any remaining pill fragments after $30 \mathrm{~min}$. Drug-related adverse effects and patient satisfaction were recorded.

\section{Followup}

Subjects were asked to return for examination on $2^{\text {nd }}, 14^{\text {th }}$ day and after 6 weeks or in between if they had any complaint like prolonged bleeding per vaginum, purulent or foul smelling vaginal discharge or dizziness with syncope attack. Vaginal ultrasonography was taken at day 14 to look for any retained products of conception. If the pregnancy was still viable at day 14 , termination was done by surgical method. If there was a non-viable gestational sac, a choice to wait up to 42 days versus surgical abortion was offered. Patients reporting with incomplete abortion and haemorrhagic morbidity were offered immediate surgical evaluation. Success was defined as expulsion of products of conception with no need for surgical intervention. Drug-related adverse effects in term of altered taste, nausea, vomiting, diarrhoea, shivering and fever were noted.

\section{Statistical Analysis}

Data analysed with the help of computer software Microsoft excel and Epi-info for window. For quantitative variables, means and standard deviation were calculated. Qualitative variables were described as frequencies and proportions. Chi square test and unpaired $t$ test were used for statistical evaluation, and $\mathrm{p}$ value $<0.05$ was taken as statistically significant.

\section{RESULTS}

Various demographic parameters were comparable in both groups as shown in table 1 . The mean age of the women using vaginal regimen was $26.44 \pm 3.24$ years and those using buccal regimen was $26.72 \pm 3.12$ years. Mean period of gestation was $6.21 \pm 0.34$ weeks in vaginal group and $6.22 \pm$ 0.26 weeks in buccal group which were comparable.

The efficacy as judged by complete abortion was $88 \%$ in group A and $94 \%$ in group B. At 2 weeks followup, six patients were found to be having retained products of conception in group A (Vaginal group). These six patients were given misoprostol (400 $\mathrm{mcg}$ ) and were called for followup after 1 week. Four patients had complete abortion and two had surgical intervention. In buccal group, three patients were found to have retained products of conception which were given repeat misoprostol $(400 \mathrm{mcg})$. Two patients had complete abortion at 1 week followup. One patient underwent surgical intervention. $24 \%$ in vaginal group and $16 \%$ in buccal group had contraceptive failure and wanted medical abortion. $74 \%$ in vaginal group and $84 \%$ in buccal group had completed their family and opted for medical abortion. Table 2 shows that there was no statistically significant difference between the two groups with regards to indication of abortion $(p=0.31)$. Statistical significant adverse effect noticed was altered taste which was perceived by $12(24 \%)$ of women in buccal group ( $p<0.05$ ). Nausea was perceived by 14 (28\%) women in vaginal group. Two patients in buccal group had shivering and two had fever in vaginal group (Table 3 ).

Analgesia requirement was same in both the groups. In vaginal group, $88 \%$ of patients were satisfied and $92 \%$ in buccal group were satisfied which did not reach statistical significance $(p=0.49)$ (Table 4$)$.

\begin{tabular}{|c|c|c|c|c|}
\hline \multicolumn{2}{|c|}{ Parameter } & $\begin{array}{c}\text { Group A } \\
\text { (Vaginal) } \\
\text { N = 50 }\end{array}$ & $\begin{array}{c}\text { Group B } \\
\text { (Buccal) } \\
\text { N = 50 }\end{array}$ & P \\
\hline $\begin{array}{c}\text { Mean age } \\
\text { (years) }\end{array}$ & & $\begin{array}{c}26.44 \pm \\
3.24\end{array}$ & $\begin{array}{c}26.72 \pm \\
3.12\end{array}$ & 0.66 \\
\hline $\begin{array}{c}\text { Socio- } \\
\text { economic } \\
\text { State }\end{array}$ & Lower & $20(40 \%)$ & $20(40 \%)$ & \multirow{2}{*}{0.50} \\
\cline { 2 - 5 } & Upper & $30(60 \%)$ & $30(60 \%)$ & 0.56 \\
\hline Background & Urban & $42(84 \%)$ & $44(88 \%)$ & 0.56 \\
\hline
\end{tabular}




\begin{tabular}{|c|c|c|c|}
\hline Rural & $8(16 \%)$ & $6(12 \%)$ & \\
\hline Mean BMI kg/m & & $22.98 \pm$ & $22.93 \pm$ \\
2.01 & 2.16 & 0.90 \\
\hline Mean period & $6.21 \pm$ & $6.22 \pm$ & \multirow{2}{*}{0.86} \\
of gestation (weeks) & 0.34 & 0.26 & \\
\hline \multicolumn{4}{|c|}{ Table 1. Demographic Parameters } \\
of Two Groups of Patients \\
\hline
\end{tabular}

\begin{tabular}{|c|c|c|}
\hline $\begin{array}{c}\text { Indication } \\
\text { of Abortion }\end{array}$ & Group A & Group B \\
\hline Contraceptive failure & $12(24 \%)$ & $8(16 \%)$ \\
\hline $\begin{array}{c}\text { Family size completed } \\
\text { (Number of children) }\end{array}$ & $38(74 \%)$ & $42(84 \%)$ \\
\hline Total & $\mathbf{5 0}$ & $\mathbf{5 0}$ \\
\hline \multicolumn{2}{|c|}{$\mathrm{p}=0.31$} \\
\hline
\end{tabular}

Table 2. Indication of Abortion in Two Groups of Patients

\begin{tabular}{|c|c|c|c|}
\hline $\begin{array}{c}\text { Adverse } \\
\text { Effects }\end{array}$ & $\begin{array}{c}\text { Group A } \\
\text { (Vaginal) }\end{array}$ & $\begin{array}{c}\text { Group B } \\
\text { (Buccal) }\end{array}$ & $\begin{array}{c}\mathbf{p} \\
\text { value }\end{array}$ \\
\hline Altered Taste & $0(\%)$ & $12(24 \%)$ & $<0.05(\mathrm{~S})$ \\
\hline Nausea & $10(20 \%)$ & $14(28 \%)$ & $>0.05(\mathrm{NS})$ \\
\hline Vomiting & $0(0 \%)$ & $2(4 \%)$ & $>0.05(\mathrm{NS})$ \\
\hline Diarrhoea & $0(0 \%)$ & $0(0 \%)$ & $>0.05(\mathrm{NS})$ \\
\hline Shivering & $0(\%)$ & $2(4 \%)$ & $>0.05(\mathrm{NS})$ \\
\hline Fever & $2(4 \%)$ & $0(0 \%)$ & $>0.05(\mathrm{NS})$ \\
\hline \multicolumn{3}{|c|}{ Table 3. Drug-related Adverse } \\
Effects in Two Groups of Patients \\
\hline
\end{tabular}

\begin{tabular}{|c|c|c|}
\hline Satisfaction Level & Group A & Group B \\
\hline Satisfied & $45(90 \%)$ & $47(94 \%)$ \\
\hline Unsatisfied & $5(10 \%)$ & $3(6 \%)$ \\
\hline Total & $\mathbf{5 0}$ & $\mathbf{5 0}$ \\
\hline \multicolumn{3}{|c|}{$\mathrm{p}=0.49$} \\
\hline \\
Table 4. Patient Satisfaction \\
Level in Two Groups of Patients \\
\hline
\end{tabular}

\section{DISCUSSION}

An estimated 41.6 million abortions occur annually and nearly 19 million (55\%) of them are unsafe. ${ }^{[9]}$ Almost there is one unsafe abortion for every ten pregnancies or one abortion every seven live births worldwide.[10] Induced abortion has a long history and has been facilitated by various methods including herbal abortifacients, the use of sharpened tools, physical trauma and other traditional methods. Medical abortion has a great potential of being the modern, reliable, safe and non-invasive methods of termination of pregnancy which can serve large number of women particularly in developing countries like India. The safety of procedure is therefore of global public health importance. In our study, the patients were comparable in terms of age, height, weight, and BMI mean period of gestation and socioeconomic status.

Our study showed 88\% efficacy in vaginal group and 94\% efficacy in buccal group in first trimester. The difference was not statistically significant $(\mathrm{p}>0.05)$. Our results corroborated well with trial conducted by Middleton et al in which the efficacy rate for complete abortion with $800 \mathrm{mcg}$ misoprostol was $95 \%$ in the buccal group and $93 \%$ in the vaginal group. ${ }^{[7]}$ Large retrospective analysis of medical abortion safety conducted by PPFA, Inc, since 2001 showed a decrease over time in the serious infection rate with a change from vaginal to buccal misoprostol and similar efficacy.[11]

Geetika Garg et al conducted a randomised controlled trial observing $96 \%$ success rate in buccal group and $88 \%$ in vaginal group. Our study findings corroborated with the study.[12] Fjerstad $\mathrm{M}$ et al observed $98.3 \%$ success in for medical abortion with $200 \mathrm{mg}$ of mifepristone combined with 800 mcg of self-administered buccal misoprostol within 24 48 hours.[13] In our study, no statistical significant differences were reported in the rates of drug-related adverse effects which was consistent with the study by Middleton et al[7] and Geetika Garg et al.[12]

Nausea in both the groups $(14 \%$ in buccal and $10 \%$ in vaginal group) and altered taste $(12 \%)$ was an additional adverse effect of buccal route of administration. Analgesia was required in one patient in each group which was administered orally. The satisfaction rate as asked by a questionnaire was $90 \%$ in vaginal and $94 \%$ in buccal group.

\section{CONCLUSION}

Termination of an early unwanted pregnancy is a basic concern of a woman. For this purpose, she has been using several traditional methods and remedies since very ancient times. After legalisation of medical termination of pregnancy, surgical methods were the only available option. Previously medical abortion was approved only for cases up to 49 days of gestational age, but now has been approved by WHO and FOGSI for cases up to 63 days or nine weeks of gestational age. Medical abortion with $200 \mathrm{mg}$ of oral mifepristone and $800 \mathrm{mcg}$ buccal misoprostol has been proven to be as effective, safe, reliable and less invasive method as compared to vaginal route of misoprostol. Thus, buccal regimen has an acceptable success rate and may provide a new treatment alternative for women uncomfortable with vaginal misoprostol in the first trimester induced abortion.

\section{REFERENCES}

[1] Kurtkoti K. FOGSI focus on medical abortion. 2010; $p$ $5,27,31$.

[2] Malcolm P, Campbell M. History of contraception. Gynaecol Obstet 2008;6(8):9-21. http://big. berkeley.edu.

[3] Unsafe abortion: global and regional estimates of incidence of unsafe abortion and associated mortality in 2003. Fifth edition. World Health Organization Cataloguing-in-Publication Data. p. 1, 4-6.

[4] Consortium on National Consensus for Medical Abortion in India. New Delhi. http://www.aiims.edu/aims /events/Gynae website /ma-finalsite/introduction.html. 2008.

[5] Medical Termination of Pregnancy act. MTP act (1971) and MTP rule (1972): Govt. of India.

[6] Megh M. FOGSI. Comprehensive abortion care and post abortion contraception, FOGSI focus. 2012; p. 15.

[7] MiddletonT, Schaff E, Fielding SL, et al. Randomized trial of mifepristone and buccal or vaginal misoprostol for abortion through 56 days of last menstrual period. Contraception 2005;72(5):328-32.

[8] Schaff EA, DiCenzo R, Fielding SL. Comparison of misoprostol plasma concentrations following buccal and sublingual administration. Contraception 2005;71(1):22-5. 


\section{Jemds.com}

[9] Abortion worldwide: a decade of uneven progress. Guttmacher Institute. 2009; p. 17.

[10] WHO, unsafe abortion: Global and Regional estimates of the incidence of unsafe abortion and associated mortality in 2003; p. 14.

[11] American College of Obstetricians and Gynaecologists. Practice bulletin No.143: medical management of first trimester abortion. Obstet Gynecol 2014;123(3):67692.
Original Research Article

[12] Garg G, Takkar N, Sehgal A, et al. Buccal versus Vaginal misoprostol administration for the induction of the first and second trimester abortions. J Obstet Gynaecol India 2015;65(2):111-6.

[13] Fjerstad M, Sinin L, Lichtenberg ES, et al. Effectiveness of medical abortion with mifepristone and buccal misoprostol through 59 gestational days. Contraception 2009;80(3):282-6. 